\title{
How pandemic affects occupants' buildings perception: questionnaires investigation and preliminary results
}

\author{
Iole Nardi ${ }^{1, *}$ and Domenico Palladino ${ }^{1}$ \\ ${ }^{1}$ ENEA (Italian National Agency for New Technologies, Energy and Sustainable Economic \\ Development), DUEE Dept., 00123 via Anguillarese 301 Santa Maria di Galeria (Rome), Italy
}

\begin{abstract}
The COVID-19 pandemic has changed the living habits all over the world. Countries experienced multiple lockdowns, causing offices, restaurants, school and almost all the economic activities to close. The saying "stay home stay safe", to which we were invited for preventing the virus spread, and the rise of smart-working, lead to an exponential increase in the time spent in our homes. In this sense, the way to live our homes has changed. Spaces and rooms that (before pandemic) were occupied for just a few hours a day, have become the main places for studying, working, playing or even have fitness. More than ever, people had to face the energy related problems of their house: air leakages, energy losses, expensive billings, and thermal discomfort. This study arises from considerations on buildings use after the pandemic, and it addresses the consequences of COVID-19 to building perception. Anonymous questionnaires were proposed broad wide, asking through a multi-stage survey to compare the feeling before and after the pandemic, also in comparison to the billing of the energy carriers. Results have been analysed, showing how the pandemic has changed the living perception.
\end{abstract}

\section{Introduction}

In the last year and months, the spread of pandemic due to COVID-19 has imposed confinement measures: many activities were stopped, other had the possibility to proceed, offices were almost desert, whilst the smart-working has been highly encouraged to limit the possibility of workers of being infected. This led to a crisis (beyond the sanitary one which was ongoing) of many collateral sectors: from transportation to the energy demand.

A recent report [1] on the Italian energy system highlights that primary sources for electric generation suffered for a decrease of 2-3 Mtep in 2020 (with respect to 2019), but in the first quarter of 2021 they are increasing (of about 1.5\%) with respect to the homologous of 2020 (although being at $-5 \%$ with respect to the homologous of 2019).

In 2020, the pandemic has caused a reduction of primary energy need of $-14 \%$ in March, $-29 \%$ in April, and $-22 \%$ in May, and of $-15 \%$ in June. Then, the reduction of severity of confinement measures (during summertime) determined an increase in the needs, but the

* Corresponding author: iole.nardi@enea.it 
second pandemic wave in fall season caused other reductions $(-6 \%$ in November and $-8 \%$ in December). As a whole, the first pandemic caused a more pronounced reduction that the second one.

Reducing trends emerged in all Countries, although the impact of COVID-19 outbreak depends on several factors (urban energy systems, confinement measures, infrastructures, socio-economy, etc) [3]. Energy challenges and energy opportunities emerged worldwide due to this outbreak [4].

In any case, all these considerations are subsequent the confinement measures that, in turn, had changed our lives and living habits. Indeed, many employees had to work from home, students experienced the on-line schools, and even fitness was made in a spare room. The schedules had changed, and some studies tried to figure out what occurred or might occur in this (or more severe) situations. In [2] the effects of short-term lockdown on the energy use on the municipality of Florianopolis (in Brazil) were studied, proving the intensity of vital and/or stand-by loads which otherwise were difficult to measure and reveal.

Indeed, in [3], the impact of COVID-19 on the energy demand at district level in Sweden (thus including both residential and commercial buildings, offices, and school) has been simulated according to the new schedules and use of such buildings and figuring out different level of confinement measures (including a full lock down).

Other works $[5,6]$ focus on the need for rethinking the HVAC system to provide fresh air intake in building without compromising the energy efficiency and the risk of airborne transmissions, while ensuring thermal comfort.

An interesting paper [7] analyses the energy consumption variation due to lockdown in different countries in residential buildings: the overall electricity demand decreased (due to the impact on commercial buildings and manufacturing sectors) while the housing sector' energy consumption increased by as much as $30 \%$ during the full 2020 lockdown period. The work [7] also shows that the increase of buildings energy consumption is caused by the new schedules and occupancy rates, that in turn led to an increased use of energy services, like heating, air conditioning, lighting, and appliances.

The new occupancy rates might have also affected the way we relate to the building itself, i.e. our perception of rooms, needs and energy consumption.

To assess this, it is not possible to rely on simulation. Rather, being this topic a subjective matter, a survey is needed.

These considerations moved this preliminary research activity, through which anonymous questionnaires were proposed to unrelated people.

People were asked, through a multi-stage survey, to compare the feeling before and after the pandemic, also considering the billing for energy services, and they were asked to identify whether their homes are still comfy for them. Results have been analysed, showing how the pandemic has changed the living perception.

\section{The questionnaire}

Questions of the survey were conceived as a preliminary questionnaire, which will be improved in further studies to have more detailed info not only related to the pandemic context.

The proposed questionnaire, which was spread by sharing a web link, has foreseen a multi-stage survey: interviewee has the choice to access to the following stages, which were subsequent. The total number of questions is 70 , and the main structure is proposed in Fig. 1. 


\begin{tabular}{|c|c|c|c|c|}
\hline \multirow[t]{2}{*}{ STAGE 1} & \multicolumn{4}{|c|}{$\begin{array}{c}\text { GENERAL INFO } \\
\text { ment, smart worker (after pandemic) }\end{array}$} \\
\hline & (3) & & & OVID \\
\hline \multirow[t]{2}{*}{ STAGE 2} & $\begin{array}{l}\text { Work activity } \\
\text { Workplace } \\
\text { Home area } \\
\text { Billings } \\
\text { Energy services }\end{array}$ & $\begin{array}{l}\text { Solar radiation } \\
\text { Artificial lighting } \\
\text { Air exchange rate } \\
\text { Quality of life } \\
\text { Hours spent at home }\end{array}$ & $\begin{array}{l}\text { Work activity } \\
\text { Workplace } \\
\text { Home area } \\
\text { Billings } \\
\text { Energy services }\end{array}$ & $\begin{array}{l}\text { Solar radiation } \\
\text { Artificial lighting } \\
\text { Air exchange rate } \\
\text { Quality of life } \\
\text { Hours spent at home }\end{array}$ \\
\hline & \multicolumn{4}{|c|}{ 位 ENERGY PERFORMANCE CERTIFICATE (EPC) } \\
\hline STAGE 3 & $\begin{array}{l}\text { EPC availability } \\
\text { Net surface (heated and cooled) } \\
\text { Gross volume (heated and cooled) } \\
\text { A/V }\end{array}$ & 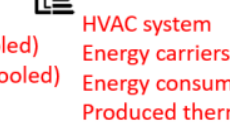 & \multicolumn{2}{|c|}{$\begin{array}{l}\text { Produced electric energy } \\
\text { EPgl, ren } \\
\text { Energy class } \\
\text { Energy billing }\end{array}$} \\
\hline
\end{tabular}

Fig. 1. The main structure of the questionnaire

The first stage has questions on the interviewee (like age, educational attainment, employment) and on the building (municipality, construction year, ownership, details on HVAC system and on lighting system).

The second stage has questions on the activities before and after the pandemic, like the work activity and place, the number of hours spent at home and the yearly billing. Moreover, people were asked to express satisfaction rates on the quality of life, on the solar radiation into the house as well as of the artificial lighting into the house. Finally, a ranking on the energy services billing was asked, to assess the COVID-19 restriction and the increased number of hours at home has changed the way such services weight on the final perception.

The third stage has questions on the Energy Performance Certificate (EPC) of the house: this was needed to know how many owners (or tenants) have a sensitivity on this topic, and how many of them are willing to answer.

All answers were mandatory, but there was also the possibility of expressing final remarks.

\section{Results}

In the following, the main results from the questionnaire are presented.

About half of interviewee is 31-40 years old (Fig. 2), and the home they are living in is mainly a property house, and none of the interviewee aged $>60$ is a tenant.

It is worth considering that the age range 31-60 is that who mainly experienced the smartworking, and whose living habits have deeply changed, and they account for the large majority of interviewee. 


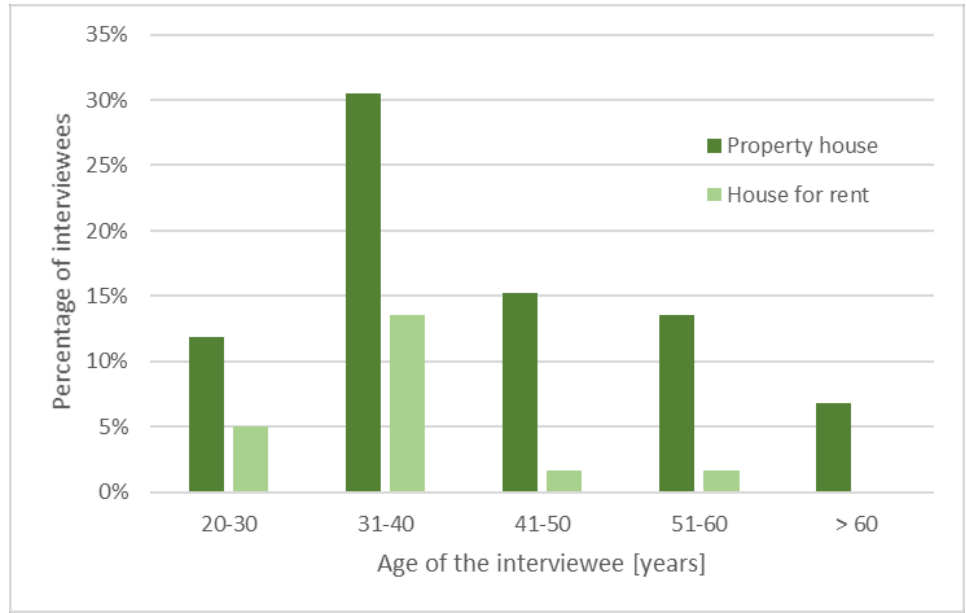

Fig. 2. Interviewee age and ownership

Half of the house where people live were built before 1990 (Fig. 3), which implies poor energy efficiency, whilst building built after 2010 are about the $8 \%$ of the total. The $75 \%$ of interviewees' house falls in climatic zone E (Fig. 4).

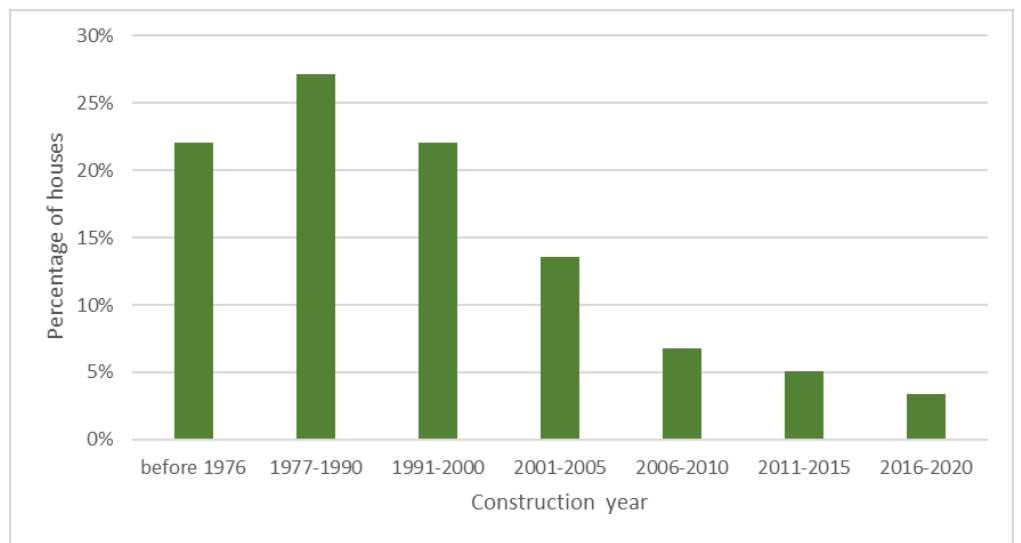

Fig. 3. Houses construction year

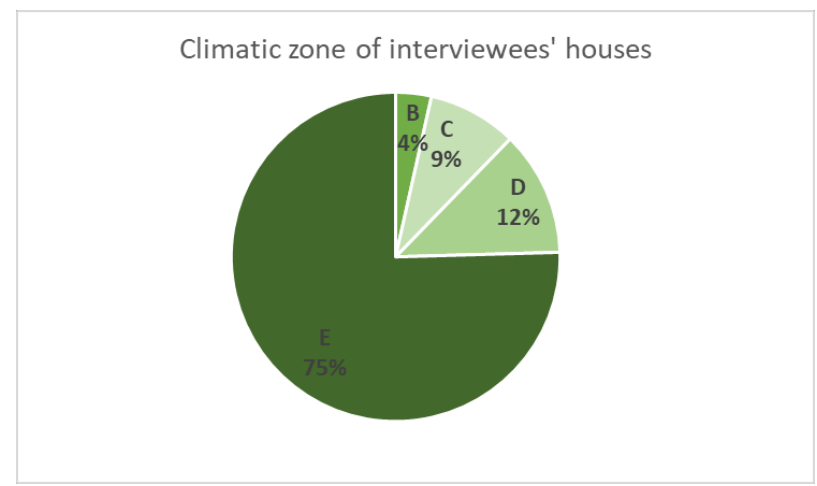

Fig. 4. Climatic zone (according to the Italian law) of the interviewees' houses 
Another question concerning the house feature regards the presence of gardens and balconies. Indeed, many people complied about the scarcity of room or places where to have fresh air or where to spend their time. However, the result from the survey (Fig. 5) confirms that half of the houses has at least one garden and almost all of them also have a balcony. Indeed, there are a few people who didn't have garden nor balcony. The building typology, with their urban context, are summarized in Fig. 6

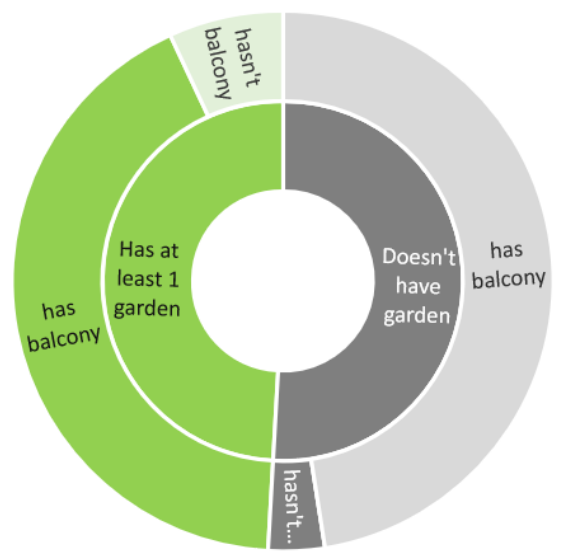

Fig. 5. House features (gardens and balconies)

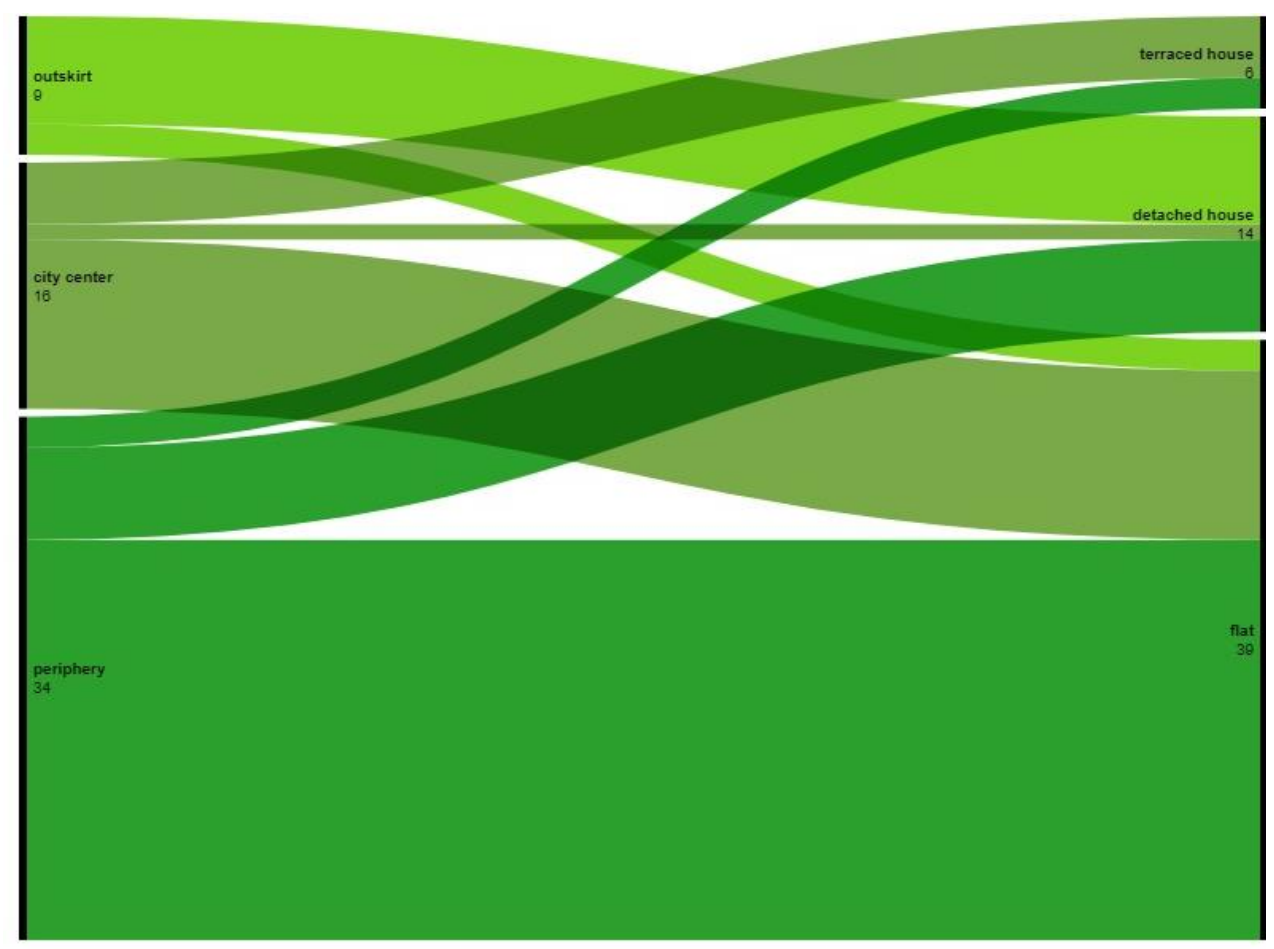

Fig. 6. Building typology and urban context 
Only two interviewees decided not to proceed with the second stage, that regarded the life before and after the COVID-19 outbreak.

First of all, it is necessary to consider what did change after the pandemic.

Indeed, people were asked to indicate the number of hours spent at home (including nights) (Fig. 7). The bell trend that occurred before pandemic (with a peak in the range 1113 hours) has now a different pattern where, as foreseeable, the number of hours definitely increases toward the 20-22 and 23-24 ranges.

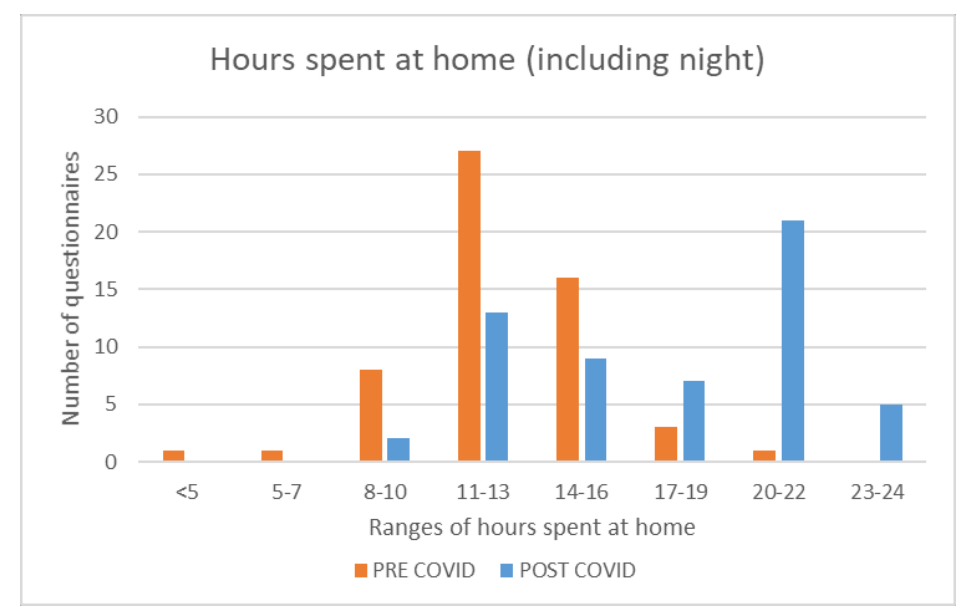

Fig. 7. Changes in living habits: ranges for the number of hours spent at home (including night)

The trend of Fig. 7 can be also read in the sense of the changes in the working habits. In Fig. 8 the pre- and post-COVID activities are displayed, also according to the age of interviewees. It is evident that the preponderant introduction of smartworking (even when alternated to the work from office) has involved half of the interviewees. 


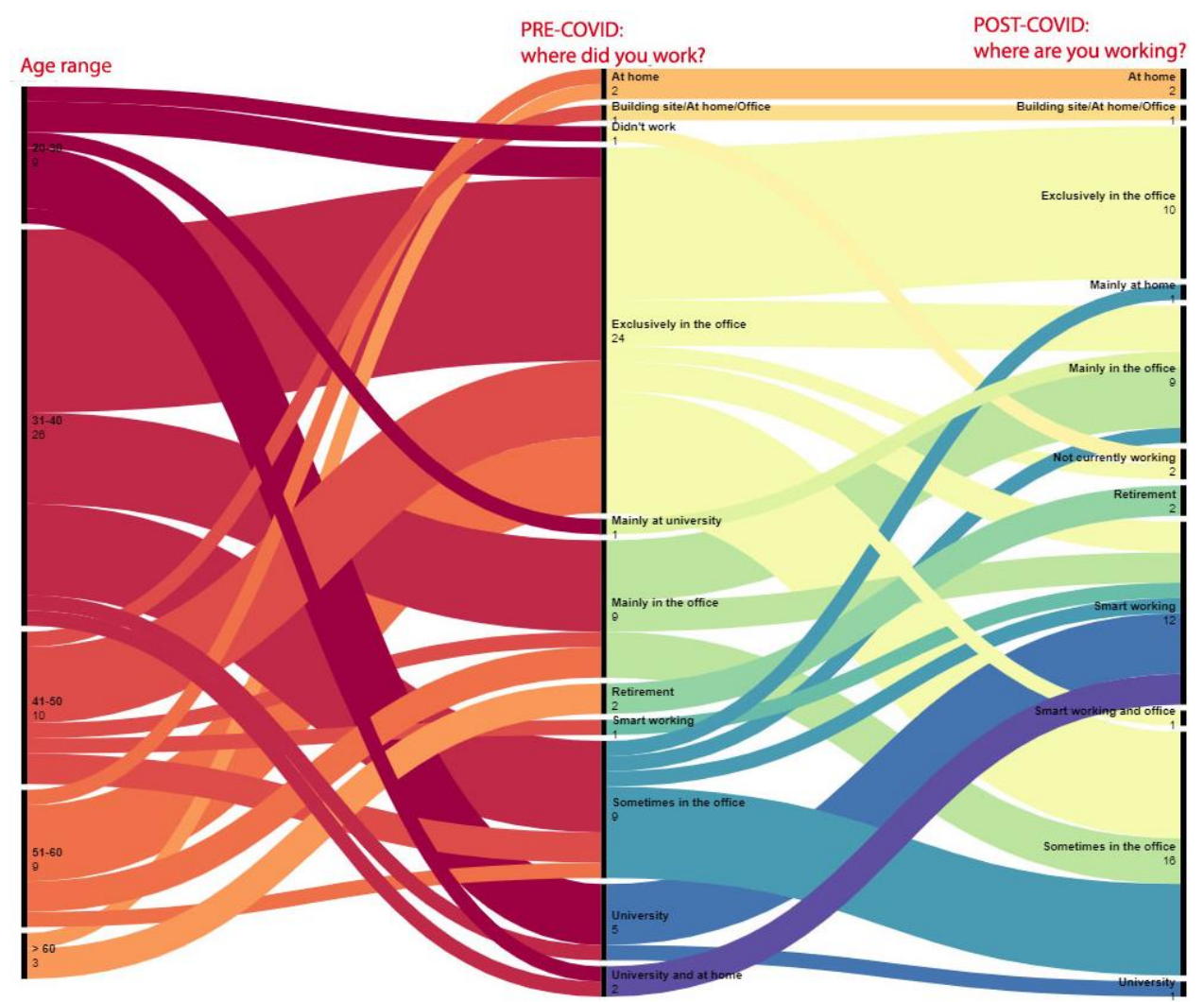

Fig. 8. Changes in living habits: place for working

The increased number of smart workers and the increased number of hours spent at home have led to the satisfaction rates on the surface of the house for housing needs expressed in Fig. 9. As a whole, the housing perception did not change too much, although it decreased the number of "very satisfied" people while it increased the number of "satisfied" people and of "unsatisfied". This implies that the interviewees consider their actual house a good place to live in, beyond some exception whose liking has diminished.

\section{The surface of my house is sufficient for my housing needs}

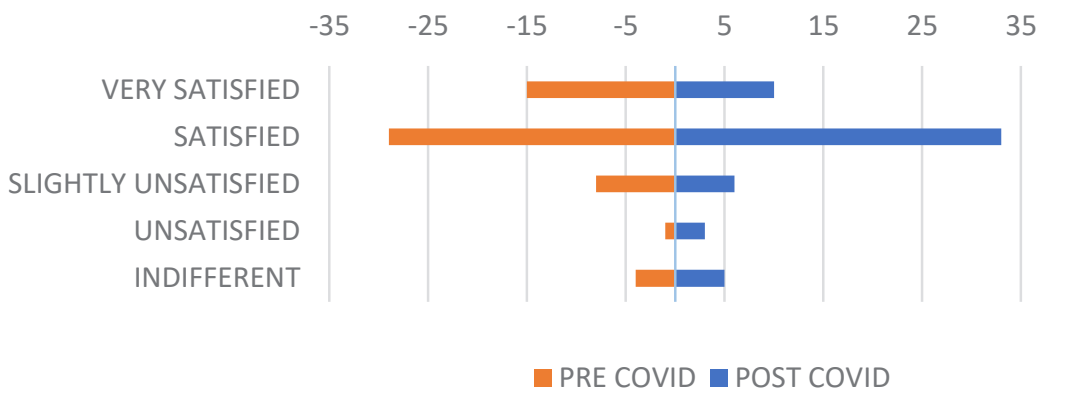

Fig. 9. Satisfaction rates on the surface of the house for housing needs 
The prolonged staying at home (during both the spring, summer and fall season) has induced people to focus on the use of lighting system and on the solar radiation in their house. The results are shown in Fig. 10. Regarding the solar radiation, the number of indifferent and unsatisfied people increased, whilst the number of satisfied people decreased. Indeed, regarding the artificial lighting, after the pandemic the number of very satisfied people decreased, while satisfied and slightly unsatisfied people has increased. In general, there is a worsening on the perception of the artificial lighting.

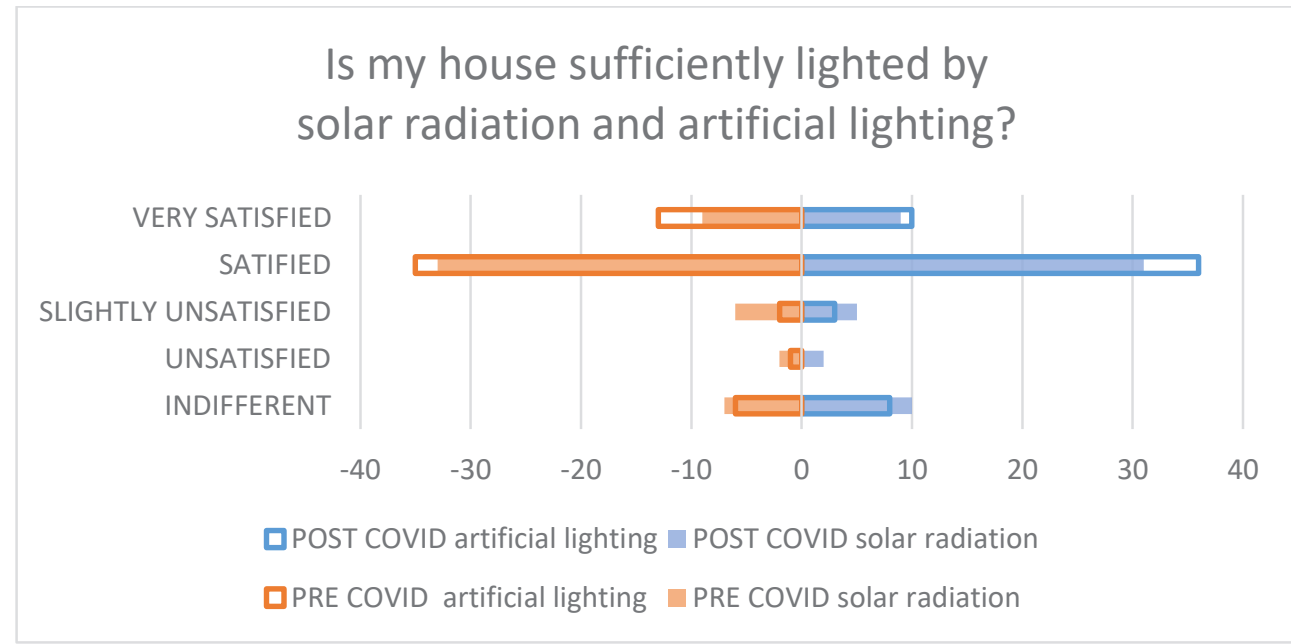

Fig. 10. Satisfaction rates on solar radiation and artificial lighting into the house

Then people were asked to rate the billing affordability (Fig. 11), considering all the energy services: in this case, the number of satisfied people increased, also confirming the results of Fig. 9.

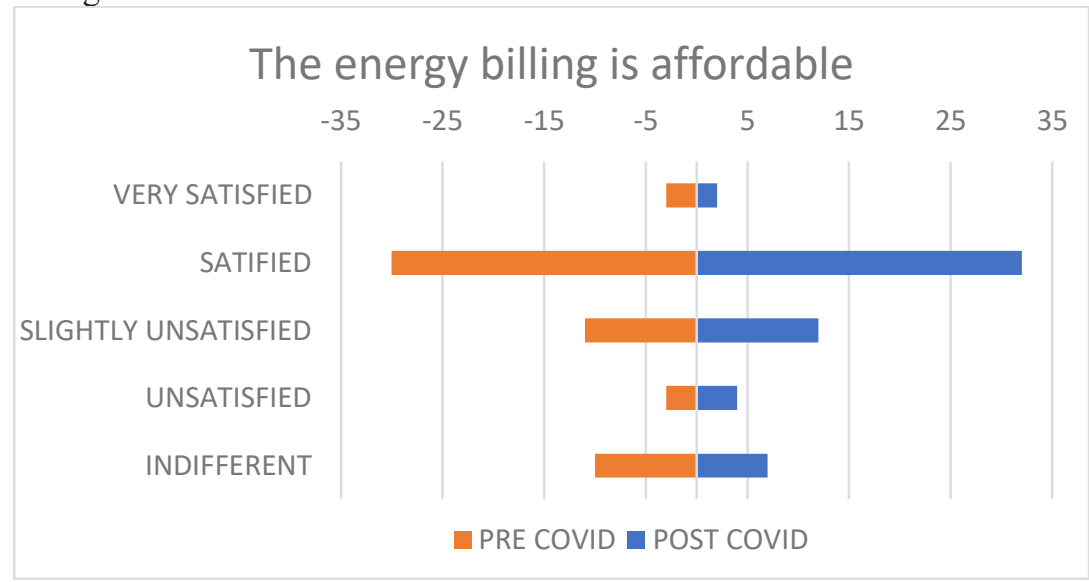

Fig. 11. Satisfaction rates on yearly billing (considering all the energy services)

Then, interviewees were asked to rank the energy services according to their relevance on the billing: results are shown in Fig. 12.

Before and after the lockdown, people consider that the more expensive service is heating, and then (in order) domestic hot water production (DHW), appliances, lighting and finally cooling (this one maybe because it is not present as energy service; moreover, it should be 
considered that the $75 \%$ of interviewees is in climatic zone E (Fig. 4)). Although the ranks are the same, votes are differently distributed of the services before and after the pandemic.

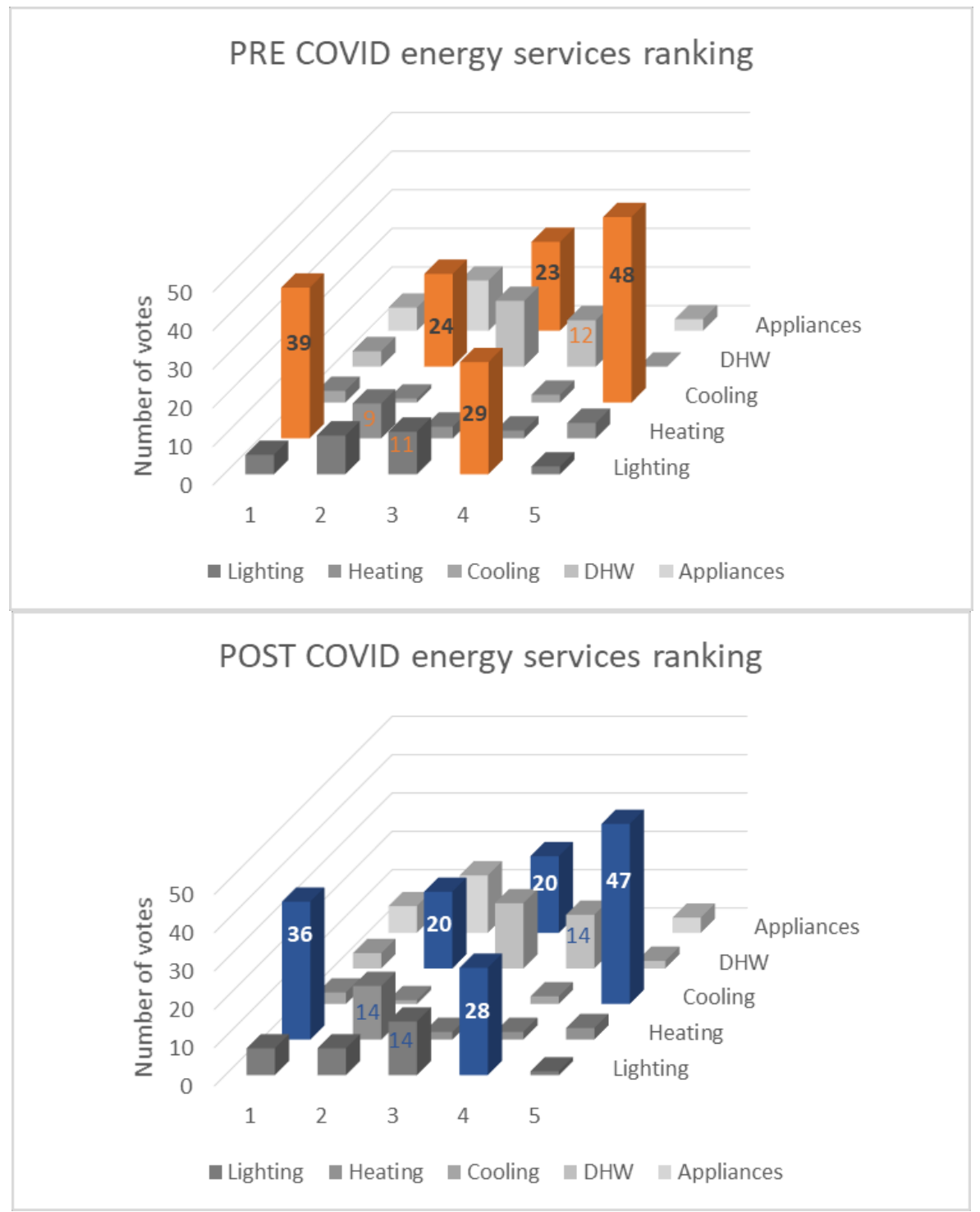

Fig. 12. Ranking on the expences for energy services

In particular, it increased the perception of the role of lighting, of appliances and of DHW. Indeed, votes distribution over each service, that was quite neat before pandemic, after the COVID-19 better recalls a bell distribution for all services (excluding cooling, for the reasons above).

This implies that the staying at home has changed the perception of the relative weight of the energy services, without changing their absolute weight.

This reflects also in the overall increase of the energy billing (Fig. 13): the number of people whose expenses were in the range 201-500€ and over $1000 €$ is quite the same before and after the COVID-19, whilst it definitely increased the energy billings comprised in the range 751-1000€. Therefore, it occurred a sort of levelling for the billing. 


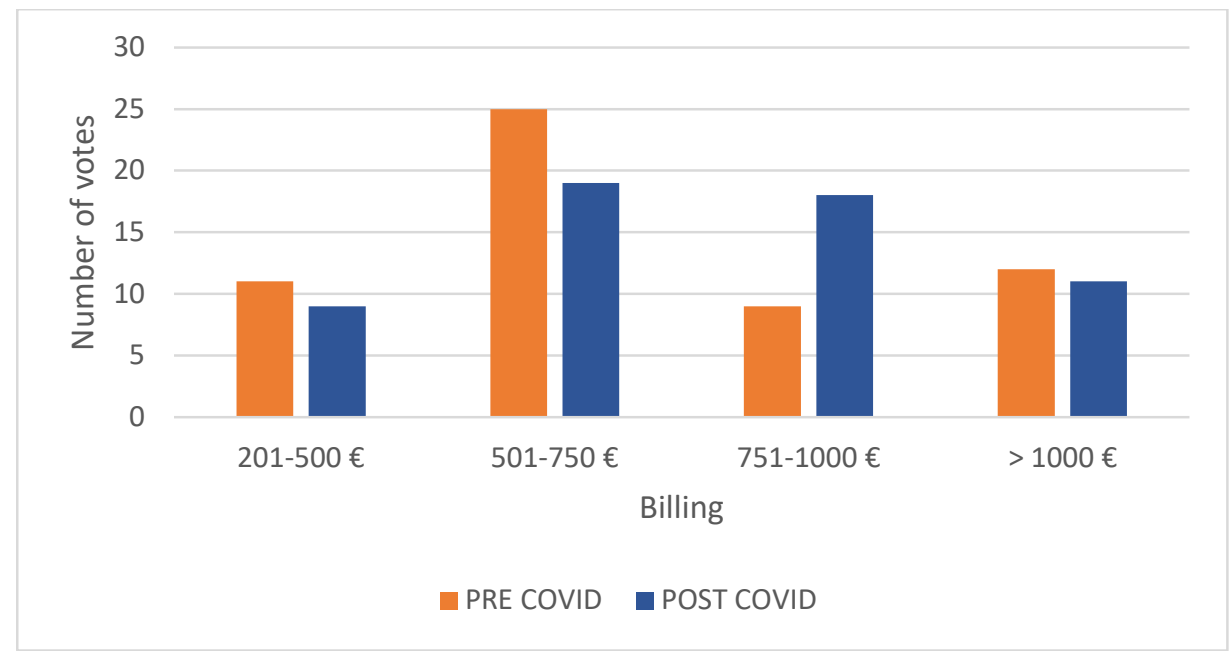

Fig. 13. Ranges for billing expences

A self-assessment of the air exchange in the house was also proposed. Results are shown in Figure 14: red and green cells represent worsened and improved rates, respectively.

\begin{tabular}{|c|c|c|c|c|c|c|}
\hline & \multicolumn{4}{|c|}{ POST COVID } & \multirow[b]{2}{*}{ TOTAL } \\
\hline & & INDIFFERENT & $\begin{array}{l}\text { SLIGHTLY } \\
\text { UNSATISFIED }\end{array}$ & SATISFIED & \begin{tabular}{|l} 
VERY \\
SATISFIED
\end{tabular} & \\
\hline \multirow{5}{*}{ PRE COVID } & INDIFFERENT & 14 & 1 & 3 & & 18 \\
\hline & SLIGHTLY UNSATISFIED & & 1 & & & 1 \\
\hline & SATISFIED & & 1 & 26 & 2 & 29 \\
\hline & VERY SATISFIED & & & 1 & 8 & 9 \\
\hline & TOTAL & 14 & 3 & 30 & 10 & \\
\hline
\end{tabular}

Fig. 14. Satisfaction rates on air exchange

Finally, a question regarded the satisfaction rate on the quality of life in the house. The general trend is quite the same, but it increased the number of slightly unsatisfied. One indifferent and one satisfied person turned into slightly unsatisfied. Two people who were very satisfied diminished their liking into "satisfied", and viceversa (two satisfied increased their liking). Therefore, in general, the is a worsening in the quality of life (4 people decreased their liking, 2 people increased it). 


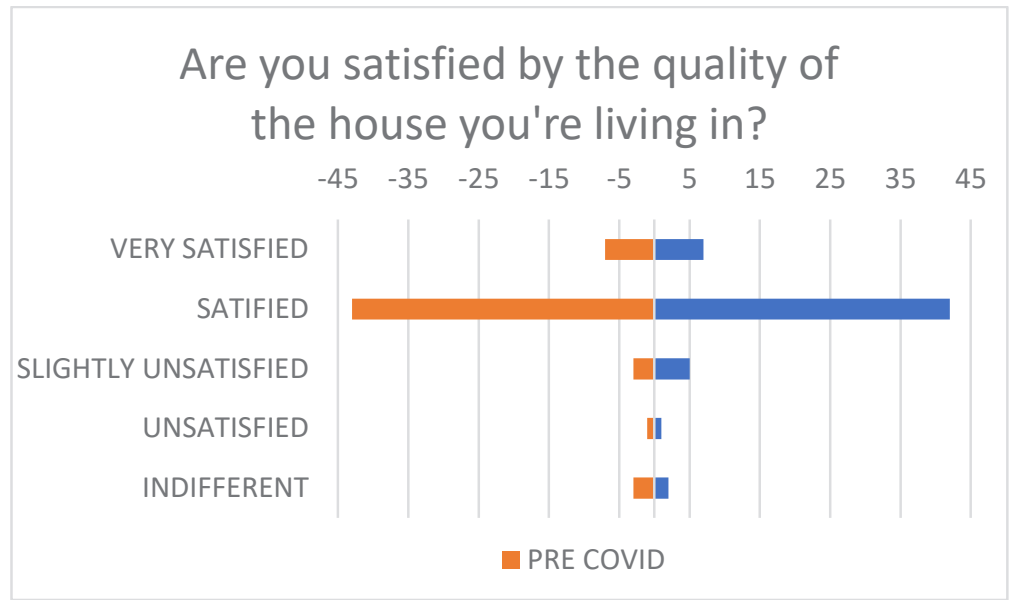

Fig. 15. Satisfaction rates on the quality of life in the house

Finally, people were asked whether to access to the third stage of the questionnaire, regarding the EPC.

Half of the surveyed person decided to proceed (Fig. 16), but many of them doesn't have an EPC. Therefore, the analysis on the remaining information, that have been provided by a short list of interviewees, have not been proposed in this work, because they might be not representative and meaningful.

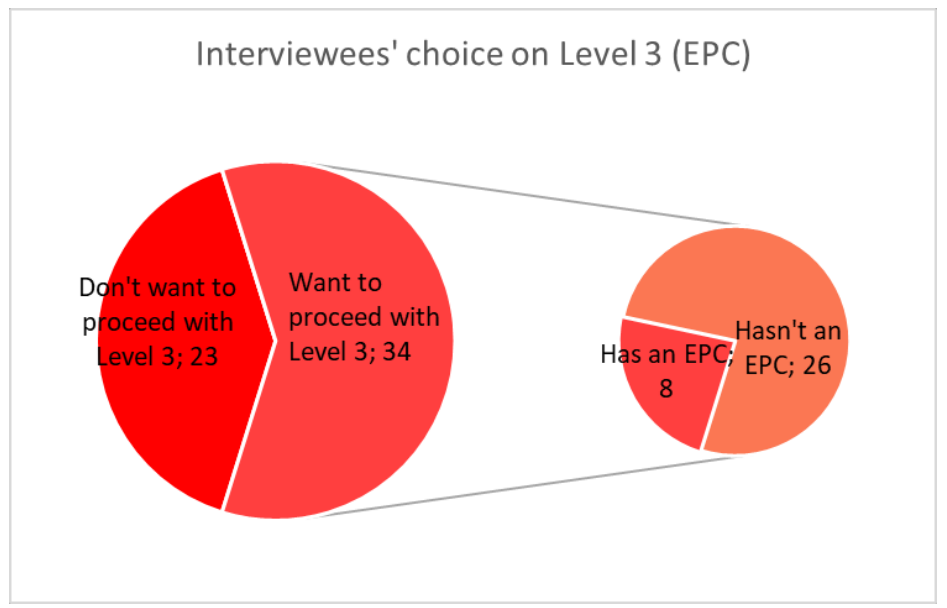

Fig. 16. Willingness to access to Level 3

\section{Conclusion}

In this work, results for an anonymous questionnaire on pandemic effect on the home perception have been proposed.

The study wants to correlate how did our living habits change due to COVID 19, and how the time spent in our home has changed the way we relate to our house. Therefore, rates on the quality of life, on the solar radiation and artificial lighting, on the expenses for the energy ranking have been asked to the interviewee. 
Results show that the sample was made up mainly by young people (31-40 years old) living the climatic zone E. The houses, mainly located in the periphery on in the outskirt, are mostly flats and detached house; their feature consist mainly of gardens and balconies. The houses have been, both before and after pandemic, sufficient for the housing needs.

The outbreak of COVID-19 changed the working habits (the majority started to smart work) and therefore the number of hours spent at home has doubled.

In turn, even the billing for the energy services has doubled, and it occurred a sort of levelling between the central ranges of the survey (501-750€ and 751-1000 $€$ ). Both before and after the lockdown, people consider that the more expensive service is heating, and then (in order) domestic hot water production (DHW), appliances, lighting and finally cooling. It is reasonable to think that the cooling service is the last in the ranking because of the climatic zone of the houses or because of the absence of energy service. Although the ranks are the same, votes are differently distributed of the services before and after the pandemic. This implies that the perception of the relative weight of the energy services has changed, without varying their absolute weight.

As a whole, the quality of life has changed (for $7 \%$ of interviewees it worsened, for $3.5 \%$ it improved).

These preliminary results open a new investigation scenario, devoted to the new living and working habits, and to the costs (like the energy cost) linked to them. It is clear that the smart working has shifted the expenses from the employer to the employee, and this might alter (in the long term) also the quality of life.

Further investigation could be focused on the thermal comfort, on correlation on the room area needed to the housing needs, on the correlation between EPC and billings, and on detailed aspects of the quality of life.

\section{References}

1. https://www.pubblicazioni.enea.it/component/jdownloads/?task=download.send\&id=4 $\underline{30 \& \text { catid }=4 \& \mathrm{~m}=0 \& \text { Itemid }=101}$

2. M. S. Geraldi, M.V. Bavaresco, M. A. Triana, A.P. Melo, R. Lamberts. Sustain. Cities Soc. 69, 102823 (2021)

3. X. Zhang, F. Pellegrino, J. Shen, B. Copertaro, P. Huang, P. K. Saini, M. Lovati. Appl. Energ. 280, 115954 (2020)

4. P. Jiang, Y.V. Fan, J. J. Klemes. Appl. Energ. 285, 116441 (2021)

5. D. Aviv, K.W. Chen, E. Teitelbaum, D. Sheppard, J. Pantelic, A. Rysanek, F. Meggers, Appl. Energ. 292, 116848 (2021)

6. L. Schibuola, C. Tambani. Energ. Build. 240, 110882 (2021)

7. M. Krarti, M. Aldubyan. Renew. Sust. Energ. Rev. 143, 110888 (2021) 